\title{
Beating Clostridium difficile infection-Insights from the Cardiothoracic Surgery Trials Network
}

\author{
John G. Augoustides, MD, FASE, FAHA
}

\footnotetext{
From the Cardiovascular and Thoracic Section, Department of Anesthesiology and Critical Care, Perelman School of Medicine, University of Pennsylvania, Philadelphia, Pa. The author receives financial support from the University of Pennsylvania.

Disclosures: Author has nothing to disclose with regard to commercial support.

Received for publication Oct 15, 2017; accepted for publication Oct 25, 2017; available ahead of print Nov 20, 2017.

Address for reprints: John G. Augoustides, MD, FASE, FAHA, Cardiovascular and Thoracic Section, Anesthesiology and Critical Care, Dulles 680, HUP, 3400 Spruce St, Philadelphia, PA 19104-4283 (E-mail: yiandoc@ hotmail.com).

J Thorac Cardiovasc Surg 2018;155:679-80

$0022-5223 / \$ 36.00$

Copyright (c) 2017 by The American Association for Thoracic Surgery

https://doi.org/10.1016/j.jtcvs.2017.10.081
}

Although Clostridium difficile infection (CDI) after cardiac surgery is uncommon, it is increasingly important. ${ }^{1-4}$ The report by Kirkwood and colleagues from the Cardiothoracic Surgical Trials Network (CTSN) in this issue of the Journal emphasizes CDI as a serious infection after cardiac surgery. ${ }^{2}$ This important trial reports a posthoc analysis from the investigation of management practices and major infections after cardiac surgery already published by the CTSN investigators. ${ }^{5}$ Recognizing that recommended best practice for antibiotic prophylaxis after cardiac surgery is a 48-hour duration, this trial identified multiple risk factors for major infection, including postoperative antibiotic duration $>48$ hours and stress hyperglycemia. ${ }^{3-5}$

In this post-hoc analysis of this multicenter trial ( $\mathrm{N}=$ 5158: 10 centers in North America), the CTSN investigators documented that CDI had an incidence of $0.97 \%$, with approximately one half of all episodes being diagnosed after discharge (Central Figure). ${ }^{2}$ Furthermore, hospital readmission and mortality were 3 and 5 times greater, respectively, in the setting of CDI. ${ }^{2}$ Akin to the mother trial, risk factors for CDI included antibiotic prophylaxis $>48$ hours and perioperative hyperglycemia. ${ }^{2}$ The authors have also highlighted the limitations of their report, including that CDI was not a predefined focus in the original trial protocol. ${ }^{2}$ These considerations have precluded further investigation of CDI with respect to diagnostic criteria, antibiotic therapy beyond prophylaxis, and gastric acid suppression with proton-pump inhibitors. $^{1-7}$ Despite these trial design issues, the CTSN investigators have underlined CDI as a major infection after cardiac surgery that requires further attention. ${ }^{2}$

This trial has added to the growing focus on CDI in the Journal due to its increasing incidence and serious sequelae. ${ }^{1-4,6,7}$ This latest report from the CTSN investigators suggests that refinements in perioperative antibiotic stewardship and glycemic control could significantly reduce the risk of CDI for cardiac surgical patients. $^{2}$ Given the significant variation in compliance levels. ${ }^{2-5}$

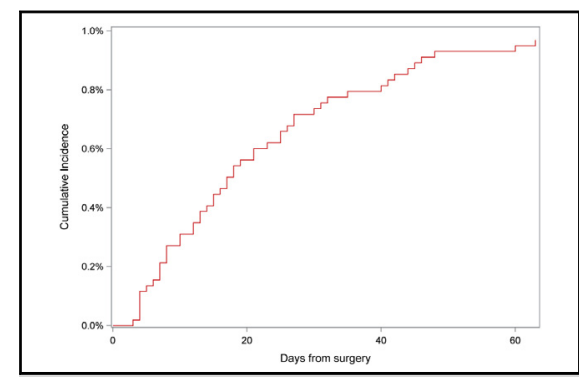

Cumulative postoperative incidence of Clostridium difficile infection.

\section{Central Message}

Although uncommon, infections with Clostridium difficile in cardiac surgical patients are important because of their significant adverse effects on mortality and major morbidity. Perioperative opportunities to reduce their clinical impact include programmatic refinements in both perioperative antibiotic stewardship and glycemic control.

See Article page 670.

with the recommended 48-hour limit for antibiotic prophylaxis after cardiac surgery, it is now a clinical imperative that we do better as a specialty with perioperative antibiotic stewardship to beat CDI at the local, regional, and national

In conclusion, Kirkwood and colleagues ${ }^{2}$ from the CTSN are to be congratulated for focusing attention on the important outcome effects of CDI after cardiac surgery and suggesting opportunities for improvement. These opportunities to beat CDI may be best realized through standardized management practices for antibiotic prophylaxis and glycemic control in a guideline-compliant fashion within and across cardiac surgical service lines throughout North America. Future trials will likely focus further on CDI for mitigation of its adverse clinical effects, as part of the broader focus on major infections after cardiac surgery. ${ }^{1-5}$ These trials could also investigate the application of novel therapies for CDI in the cardiac surgical environment. ${ }^{8}$ In the spirit of the CTSN, we could thus predict the future success against CDI by creating it: we could drive these success strategies against CDI by defining and applying this knowledge programmatically in the perioperative setting. 


\section{References}

1. Keshavamurthy SK, Koch CG, Fraser TG, Gordon SM, Houghtaling PL, Soltesz EG, et al. Clostridium difficile infection after cardiac surgery: prevalence, morbidity, mortality, and resource utilization. J Thorac Cardiovasc Surg. 2014;148:3157-65.

2. Kirkwood KA, Gulack BC, Iribarne A, Bowdish ME, Greco G, Mayer ML, et al. A multi-institutional cohort study confirming the risks of Clostridium difficile infection associated with prolonged antibiotic prophylaxis. J Thorac Cardiovasc Surg. 2018;155:670-8.e1.

3. Poeran J, Mazumdar M, Rasul R, Meyer J, Sacks HS, Koll BS, et al. Antibiotic prophylaxis and risk of Clostridium difficile infection after coronary artery bypass surgery. J Thorac Cardiovasc Surg. 2016;151:589-97.

4. Andersen ND. Antibiotic prophylaxis in cardiac surgery: if some is good, how come more is not better? J Thorac Cardiovasc Surg. 2016;151:598-9.
5. Geljins A, Moskowitz AJ, Acker MA, Argenziano M, Geller NL, Puskas JD, et al. Management practices and major infections after cardiac surgery. J Am Coll Cardiol. 2014;64:372-81.

6. Bateman BT, Rassen JA, Schneeweiss S, Bykov K, Franjlin JM, Gagne JJ, et al. Adjuvant vancomycin for antibiotic prophylaxis and risk of Clostridium difficile infection after coronary artery bypass graft surgery. J Thorac Cardiovasc Surg. 2013;146:472-8.

7. Flagg A, Koch CG, Schiltz N, Pillai AC, Gordon SM, Petterson GB, et al. Analysis of Clostridium difficile infections after cardiac surgery: epidemiologic and economic implications from national data. J Thorac Cardiovasc Surg. 2014;148: 2404-9.

8. Leffler DA, Lamont JT. Clostridium difficile infection. N Engl J Med. 2015;372: $1539-48$. 